A COMPARISON OF GRAIN SIZE MEASUREMENTS IN AL-CU THIN FILMS: IMAGING VERSES DIFFRACTION TECHNIQUES

L.M. Gignac, ${ }^{\star}$ C.E. Murray, ${ }^{*}$ K.P. Rodbell, ${ }^{*}$ M. Gribelyuk ${ }^{*}$

${ }^{*} \mid \mathrm{BM}$ T.J. Watson Research Center, ${ }^{+}$IBM Microelectronics Division gignac@us.bm.com

Numerous microscopy techniques, based on both imaging and diffraction, exist for the measurement of grain size distributions in polycrystalline thin-film samples. The accuracy of each technique is affected by three major factors: the effective resolution of the instrument relative to the characteristic grain size, the detection of the grain size through the thickness of the film, and the recognition of boundaries between adjacent grains during post-processing. When the instrument resolution is primarily considered, the measurement technique has a practical grain size measurement range, see Fig. 1 for a comparison of ranges for several measurement techniques. In bulk metallurgy grain size analysis, methodology has been developed to represent 3-dimensional grain structures from measurements taken on 2-dimensional images. ${ }^{1},{ }^{2}$ In thin films, these procedures are often simplified because many films have columnar microstructures with single grains spanning the film thick-

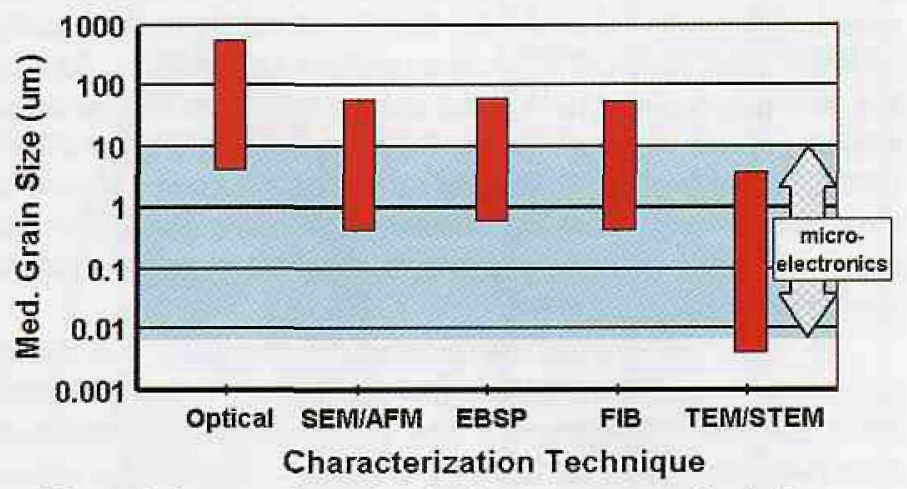

Figure 1: A comparison of grain size measurement techniques based on the practical grain size measurement range.

and the electron mean free path through the material. For example, the interaction volume can be less than $200 \mathrm{~nm}$ deep in Al films due to the oblique incidence angle (approximately $20^{\circ}$ from the surface) employed for EBSP measurements. ${ }^{3}$ The ability to accurately de- termine the location of grain boundaries in a micrograph can be a source of measurement error. Most measurement techniques rely on manual or automated recognition of grain boundaries through differential contrast between grains (STEM and FIB) or at grain boundaries (optical and AFM). Presently, commercially available software that automatically finds grain boundaries in micrographs typically renders grain boundaries inaccurately so grain structure analyses are often manual and tedious. ${ }^{4}$ EBSP delineates grains by calculating the relative misorientation of adjacent data points and therefore can be more easily automated. However, EBSP measurements are limited by the precision of determining orientations within a single grain or single crystal. Typical orientation noise of $1^{\circ}$ has been reported which can be problematic when studying low angle grain boundaries.

Due to the aforementioned factors that effect grain size measurement techniques, we studied the effectiveness of various measurement methods an a series of three $0.5 \mu \mathrm{m}$ thick Al- $0.5 \mathrm{wt} . \%$ $\mathrm{Cu}$ blanket thin films sputter deposited on either $\mathrm{Si}_{\mathrm{SiN}}(\mathrm{N})$ or $\mathrm{Si} /$ phosphorus-silicate glass $(G)$ substrates. The three films were labeled $1 \mathrm{~N}, 2 \mathrm{G}$, and $2 \mathrm{~N}$ and had median grain sizes of $0.6,1.2$, and $2.2 \mu \mathrm{m}$, respectively. The grain size measurements were initially performed by recording the thin film microstructure using various grain imaging techniques including dark field optical microscopy, $\mathrm{AFM}, \mathrm{FIB}$, and STEM. From these images, the grain boundaries were hand traced and digitized, the grain areas were measured from the digital images using Scion Image image analysis software ${ }^{6}$, and log-normal distributions of the grain areas were plotted. Median grain diameters were determined from the median grain areas assuming circular grains. The grain area distributions derived from these imaging techniques were compared to area distributions determined from EBSP orientation imaging using a HKL Technologies EBSP system with Channel 4.0 software on a LEO 1530 field emission SEM. The EBSP maps were collected on the three thin film samples tilted to $70^{\circ}$ using step sizes of $0.1 \mu \mathrm{m}$ by $0.3 \mu \mathrm{m}$ for samples $2 \mathrm{G}$ and $2 \mathrm{~N}$ and $0.02 \mu \mathrm{m}$ by $0.06 \mu \mathrm{m}$ for sample $1 \mathrm{~N}$. A grain boundary was defined as two adjacent pixels having greater than 10 degrees of misorientation. The EBSP patterns were indexed to an $\mathrm{Al} \mathrm{m} 3 \mathrm{~m}$ face centered cubic crystal structure with an indexing success rate that ranged from 75 to $90 \%$ of all of the pixels. Orientation images obtained from the EBSP data were filtered using a noise reduction routine where unindexed pixels were replaced with indexed neighbors. Though the Channel 4.0 software allows direct grain area measurements, typically a large number of small grains
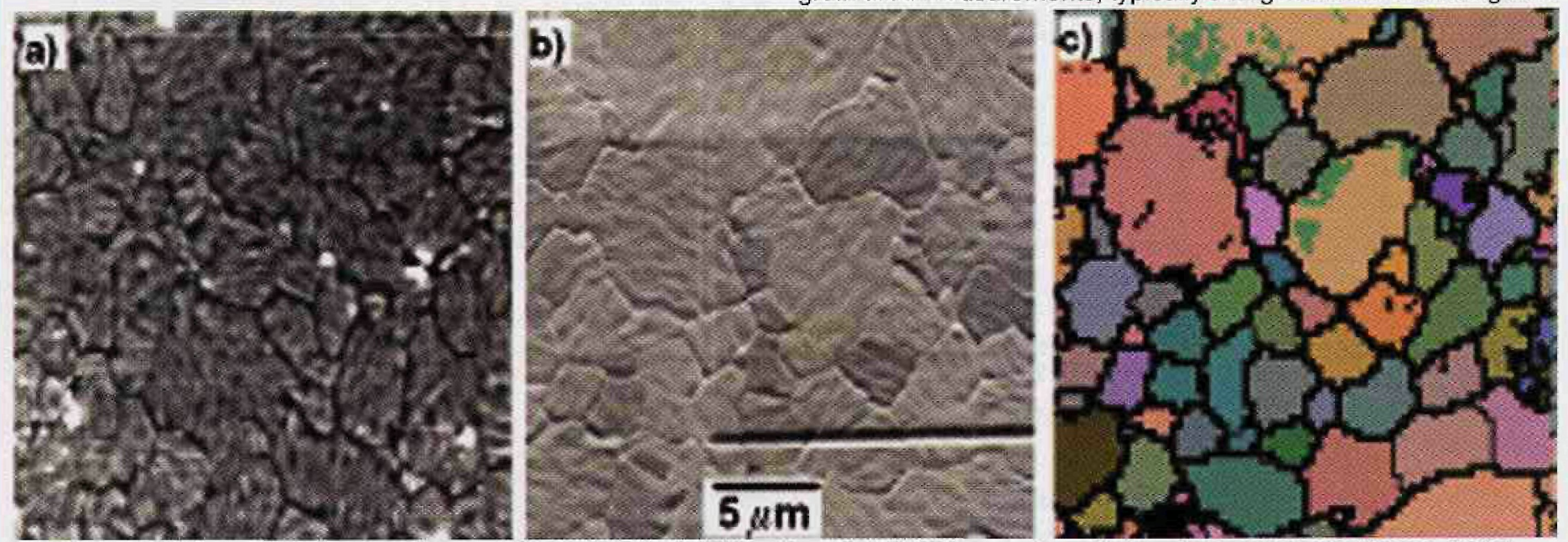

Figure 2: Various microstructural images of sample $2 \mathrm{~N}$ : a) AFM surface plot, b) FIB secondary electron image generated from a Ga ion beam, and c) EBSP grain orientation image. 


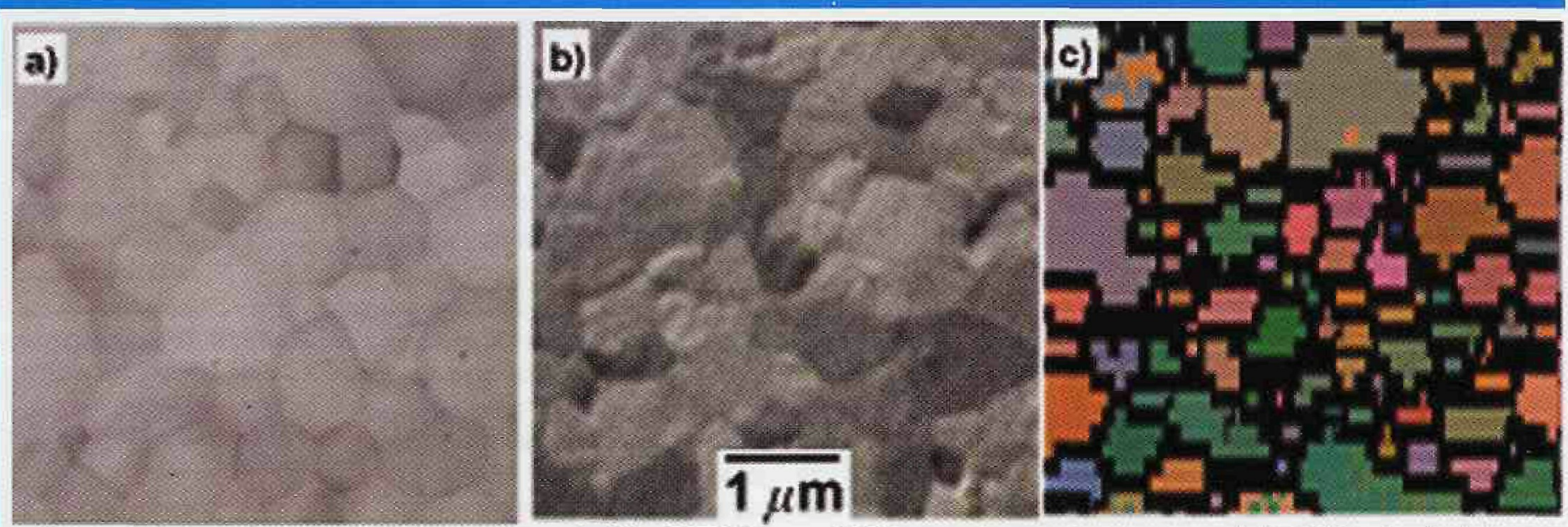

Figure 3: Various microstructural images of sample 1N: a) STEM image, b) FIB secondary electron image, and c) EBSP grain orientation image.

(e.g. single pixels = one grain) were erroneously determined with this software. Instead, black and white orientation maps were used to measure the grain areas in a manner similar to the digitized grain tracings of FIB, AFM or STEM images. Grain area distributions and median grain sizes were compared for all measurement techniques. To further understand the accuracy of EBSP in representing the grain morphology, a region of sample $2 \mathrm{~N}$ was marked and imaged in the FIB and then orientation imaged using EBSP. A comparison of the grain images for these two techniques was determined by overlaying the grain images.

Fig. 2a-c shows a comparison of grain structure images obtained by AFM, FIB and EBSP orientation imaging, respectively, taken at similar magnifications on sample $2 \mathrm{~N}$. For films with grain sizes that are relatively large for typical thin films $(>1 \mu \mathrm{m})$, all three methods imaged the grains similarly. For the finer grained sample, $1 \mathrm{~N}$, STEM imaging produced the best grain images, see Fig. 3a-c. The FIB images showed indistinct grain structures suggesting that the resolution limit was nearly reached for this technique. The EBSP orientation maps imaged the larger grains well but the smaller ones were represented by single pixels. Also, the EBSP grain morphology was not similar to the STEM and FIB imaged grains and this disparity was probably due to the step size and resolution limit of the EBSP technique. Fig. 4 shows a comparison of the median grain areas and corresponding median grain diameters for all three samples. This figure shows that there is good agreement between all the measurement techniques for the two samples with median grain diameters greater than $1 \mu \mathrm{m}$ but there is disparity between these methods in the finer grained sample, $1 \mathrm{~N}$. As with the qualitative assessment of the grain images, the finer grained sample appeared to push the resolution limit of both FIB and EBSP grain imaging methods and therefore could have been a source of measurement error. This is particularly true for the grains from the lower end of the $1 \mathrm{~N}$ grain area distribution where grain diameters are less than $0.2 \mu \mathrm{m}$.

To better understand the accuracy of grain size and shape determination using EBSP orientation imaging, sample $2 \mathrm{~N}$ was FIB marked with fiducials and then grain images were obtained from identical regions using both FIB and EBSP. Fig. 5a-b shows the FIB and EBSP images, respectively. Fig. $5 \mathrm{c}$ is an overlay image of the grains traced from the FIB image (shown in red) on the EBSP image. These images show that for large grain areas, the EBSP orientation images determine similar grain morphology as FIB imaging but some of the small grains shown in the FIB images were not imaged as distinct grains in the EBSP image. The missing small grains in the EBSP images have been attributed to choosing too large of a step size during analysis, the inability to control the $x$ and $y$ step size independently during analysis, errors in pattern recognition, and grains boundaries with $<10^{\circ}$ of misorientation.

In summary, we found that AFM, FIB, STEM and EBSP grain size analysis techniques produced grain area distributions and median grain diameter measurements that are in good agreement for films with median grain diameters greater than $1 \mu \mathrm{m}$ for Al-0.5wt.\% Cu blanket films. These techniques also 


\section{คOMInG Events}

The Materials Research Society

December 2-6, 2002, Fall Meeting, Boston, MA. info@mrs.org

$\checkmark$ Electron Cryomicroscopy Single Particle Image

Processing and Visualization Workshop

December 11-15, 2002, Houston, TX.

feinberg@bcm.tmc.edu

$\checkmark \quad$ BIOS 2003 Multiphoton Microscopy in the

Biomedical Sciences III (BO 24)

January 25-31, 2003, San Jose, California

spie@spie.org

$\checkmark$ American Society for Cell Biology

December 14-18, 2002, San Francisco, CA

www.acsb.org

$\checkmark \quad$ Microscopy NZ Conference

February 10-14, 2003, Wellington, NZ

peter.smith@agresearch.co.nz

$\checkmark$ TMS

March 2-6, 2003, San Diego, CA

ckobert@tms.org

$\checkmark \quad$ PITTCON 2003

March 9-14, 2003, Orlando, FL

www.pittcon.org

$\checkmark \quad$ Histochemical Society Annual Meeting 2003

April 11-15, 2003, San Diego, CA

johc@u.washington.edu

$\checkmark \quad$ Scanning 2003

May 3-5, 2003, San Diego, CA

www.scanning.org

$\checkmark$ Microscopical Society of Canada

June 4-6, 2003, Vancouver, BC, Canada

ech@unixg.ubc.ca

$\checkmark \quad$ Lehigh Microscopy Schools

June 8 , Introduction to SEM \& EDS

June 9-13, SEM \& X-ray Microanalysis

June 16-20, Advanced SEM

June 16-20, Quantitative X-ray Microanalysis

June 16-20, Analytical TEM

June 16-19, Characterization of Nanostructures

June 17-19, TEM Specimen Preparation

June 17-19 Atomic Force Microscopy

sharon.coe@lehigh.edu

、 Materials Research Society

April 21-25, 2003, San Francisco, CA

info@mrs.org

$\checkmark \quad$ Microscopy and Microanalysis 2003

August 3-7, 2003, San Antonio, TX

www.msa.microscopy.com

- American Society for Cell Biology 2003

December 13-17, 2003, San Francisco, CA

www.ascb.org

$\checkmark \quad$ Microscopy and Microanalysis 2004

August 1-5, 2004, Savannah, GA

www.msa.microscopy.com

$\checkmark \quad$ Microscopy and Microanalysis 2005

July 31-August 4, 2005, Honolulu, HA

www.msa.microscopy.com

Please check the "Calendar of Meetings and Courses" in the MSA journal "Microscopy and Microanalysis" for more details and a much larger listing of meetings and courses.

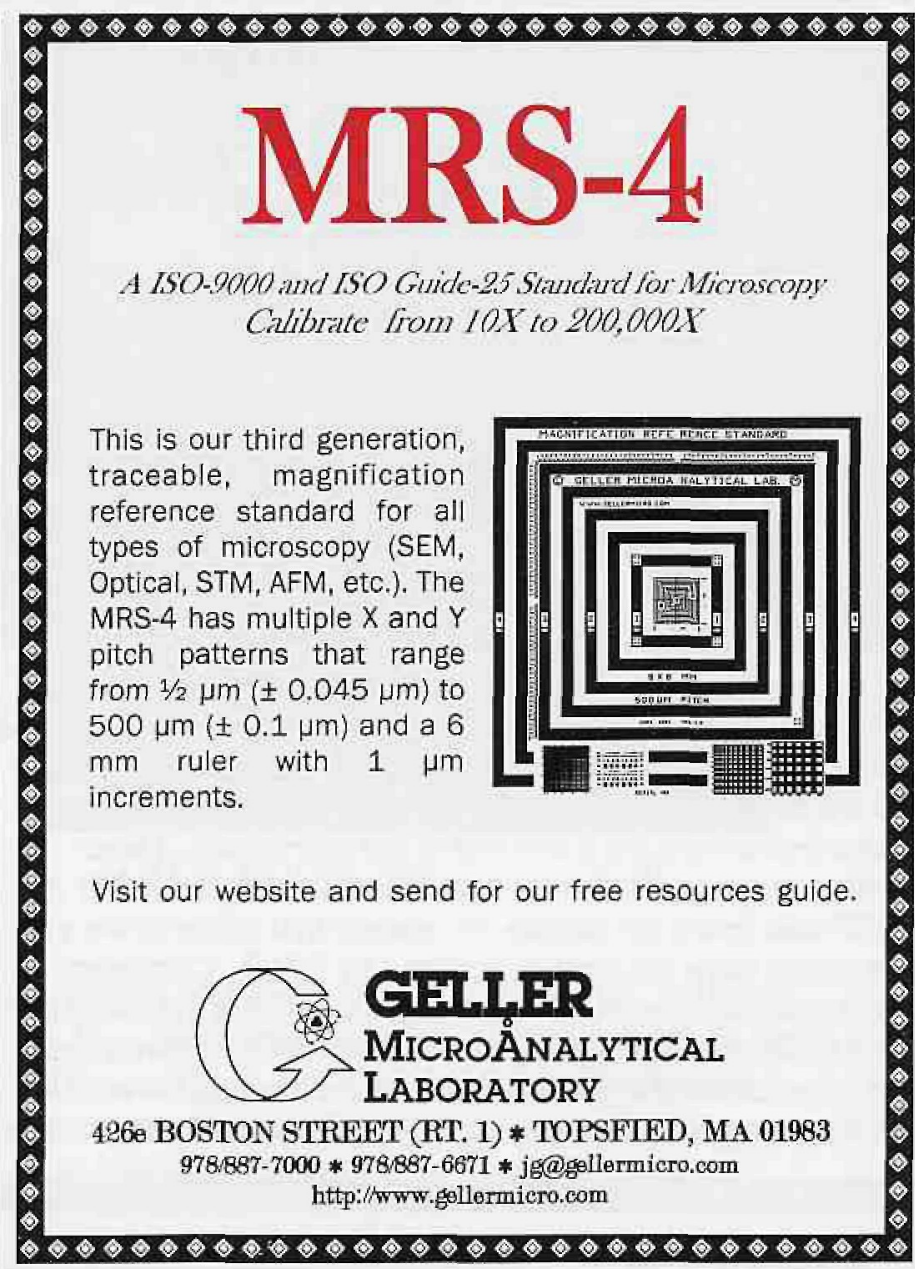

\section{IMMEDIATE POSTDOCTORAL} POSITION AVAILABLE:

CRYO-ANALYTICAL TRANSMISSION

ELECTRON MICROSCOPY OF SOFT AND HYBRID NANOSTRUCTURES

INSTITUTE FOR ENVIRONMENTAL CATALYSIS, NORTHWESTERN UNIVERSITY

Applications are invited for a full-time postdoctoral research associate within the Institute for Environmental Catalysis (IEC) at Northwestern University. The position is jointly supervised by Profs. Vinayak P. Dravid of Materials Science \& Engineering, and Prof. Jean-Francois Gaillard of Civil Engineering, at Northwestern University.

We seek a dynamic and energetic individual with prior experience in advanced electron microscopy of micobiological, geochemical, or materials systems to conduct frontier research using state-of-the-art TEM instrumentation; and design novel approaches to observe aquatic environmental particles in-situ in TEM. Hands-on experience in preparatory methods such as cryopreparation, ultramicrotomy etc. will be a strong asset, as well as knowledge of STEM-EDS, PEELS, and energy filtering.

Applications should include a vita, a brief statement of research interests, and names of at least three references including email addresses and telephone numbers.

The position is open only to those eligible for employment in the US.

Applications in PDF format should be sent by email to: v-dravid@northwestern.edu 


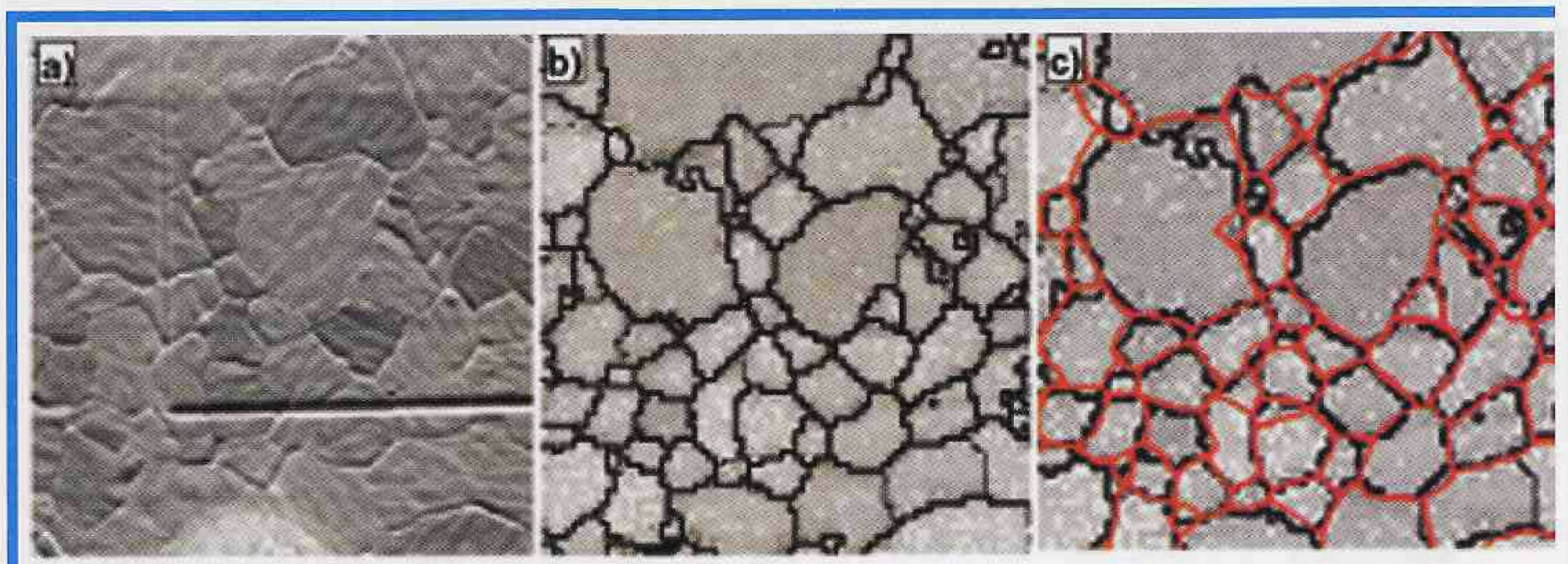

Figure 5: Direct comparison of FIB imaging and EBSP orientation imaging taken from the same region on sample 2N: a) FIB image of the box corner, b) EBSP orientation image of the same corner, and c) overlay image of F(B traced grains on EBSP image. worked reasonably well for sample $1 \mathrm{~N}$ with a median diameter of is less accurate. $0.6 \mu \mathrm{m}$ but error was probably introduced when attempting to image grains from the lower end of this distribution. Direct correlation of the grain morphology determined by both FIB and EBSP was found for sample $2 \mathrm{~N}$, except that some of the very fine grains were not always detected by EBSP. Comparing all of the grain size measurement methods, EBSP is the measurement technique of choice since it is automated, relatively rapid, and orientation information is also obtained during the analysis but there is a finite grain size limit below which this technique

\section{References:}

ASTM E112 (1996) and ASTM E1382 (1991), American Society for Testing and Materials, West Conshohocken, PA.

${ }^{2}$ R.T. DeHoff and F.N. Rhines, Quantitative Microscopy, McGraw-Hill, NY 1970

${ }^{3}$ R.A. Schwarzer, Mat. Sci. For., 287-288, 1998 P23-60.

${ }^{4}$ D.T. Carpenter, et al., J. Appl. Phys., 84, 1998 P5843-54.

${ }^{5}$ F.J. Humphreys and I. Brough, J. Microsc., 195, 1999 P6-9.

${ }^{6}$ Scion Image for PC is based on NIH Image for Macintosh, W. Rasband, U.S. National Institutes of Health, available for PC's at www.scioncorp.com.

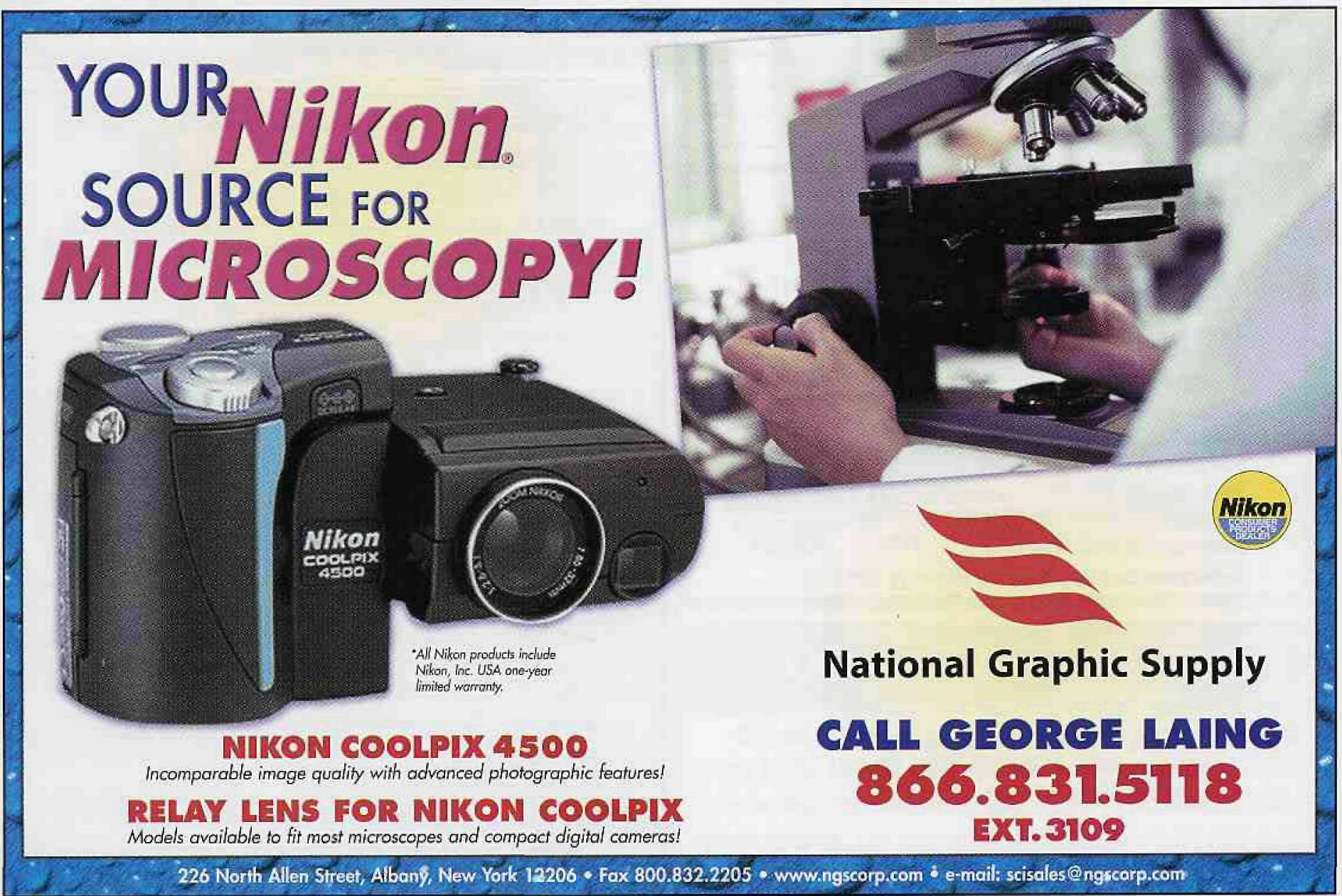




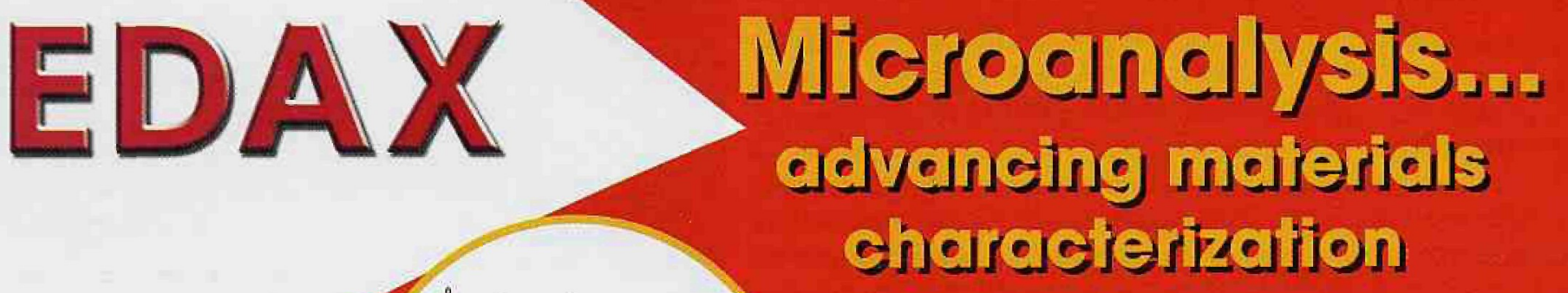

